relative cutaneous anergy often present in animals and man with inflammatory tuberculous lesions of the eye.

This concept of the pathogenesis of a tuberculous lesion offers obvious points for therapeutic attack on the disease. The first of these is enhancement of immunity, and nothing specific has been done as yet to stimulate local resistance artificially. The second is removal of the fatal tissue hypersensitivity, and this can usually be accomplished by the use of tuberculin as a desensitizing agent, and has a distinctly beneficial effect on the clinical course of the lesion. The third is the direct attack on the tubercle bacilli, and in streptomycin and promizole combined, we have a powerful weapon to this end. Doubtless other better antibiotics and sulphones will be found, but at present this combination appears the best available.

\title{
THE VASCULAR ACTION OF PILOCARPINE, ESERINE ADRENALINE AND ATROPINE, AND THEIR INFLUENCE IN PRIMARY CHRONIC GLAUCOMA*
}

\author{
BY \\ G. CRISTINI \\ BOLOGNA
}

THE rationale of the action of miotic and mydriatic drugs in glaucoma is a matter which still retains its importance, not only because our knowledge of the mechanism of the action of these drugs is still incomplete, but also because the discovery of new antiglaucomatous drugs and modern researches on the chemical mediation of the transmission of nerve impulses have amplified the problem without offering any substantial explanation. Moreover, the interpretation of the mechanism of these drugs-still an unsolved problem when they act upon the normal eye-becomes more complicated when they are considered in relation to the added problems involved in the development of a raised intraocular pressure in glaucoma.

In physiological literature we find the most diverse views regarding their effect on the ocular tension and the vascular system in the eye. Without mentioning Leber's notes in "Graefe Sämisch Handbuch," but reviewing the opinions of recent authors only, we find that in Colombo's opinion eserine and pilocarpine cause vasoconstriction, whereas Bailliart_and Bidault attribute to

* Clinica Oculistica Universitaria di Bologna, Dir., Prof. Q. Di Marzio. 
these same drugs a vasodilatory influence, particularly marked and visible in the conjunctival vessels; Michail and Vancea are in agreement with them. In Wessely's opinion eserine causes vasoconstriction in the conjunctival vessels and vasodilatation in the vessels of the iris and the ciliary body. Dieter and Thiel, on the ground of experimental findings, also suggest that these drugs cause a vasodilatation. Koellner, in a case of persistent pupillary membrane in man, was likewise able to observe a vasodilatation. Atropine, according to Colombo, causes vasodilatation as also does cocaine, a view with which Michail agrees; while according to Bailliart and Dieter, the action of this drug is vasoconstrictive. Among the most exhaustive physiological researches on this subject are those of Colle, P. M. Duke-Elder and W. S. DukeElder. On the basis of direct observation of the vessels of the iris, the registration of contractions of the extra-ocular muscles, temperature records taken in the anterior chamber and the measurement of the intra-ocular pressure in healthy animals and in artificially perfused eyes, these authors reached the following conclusions with regard to the relations of muscle contraction, vasomotor action, size of the pupil and their influence on the ocular tension :

"Adrenaline in small doses dilates the capillaries, increasing their permeability and raising the intra-ocular pressure; in large doses it constricts the vessels, lowering the intra-ocular pressure; in any dose it stimulates the plain muscle of the orbit, raising the intra-ocular pressure, and dilates the pupil, which is without effect on the intra-ocular pressure.

"Atropine dilates the minute vessels and increases their permeability, thus raising the intra-ocular pressure, and relaxes the plain muscle of the orbit, thus lowering the intra-ocular pressure.

"Physostigmine dilates the small vessels and increases their permeability, and also increases the tone of the voluntary muscles of the orbit, thus increasing the intra-ocular pressure.

" 'Pituitrin' constricts the arterioles, lowering the intra-ocular pressure, and stimulates the plain muscle of the orbit, raising the intra-ocular pressure.

"Histamine dilates the minute vessels and increases their permeability, raising the intra-ocular pressure, provided these have sufficient tone; otherwise its action is confined to a constriction of the arterioles, an action which lowers the intraocular pressure.

"Choline dilates the minute vessels and stimulates the voluntary striped muscles of the orbit, raising the intra-ocular pressure. Nicotine manifests its action entirely by stimulating the plain and striped muscle of the orbit to contract, thus raising the intra-ocular pressure.

"Curare lowers the intra-ocular pressure by relaxing the tone of the voluntary muscles."

On interpreting the action of these miotic and mydriatic drugs in glaucoma, however, all the hypotheses which have been advanced do not seem to fit in accurately with the results obtained with these physiological researches. Among the more popular hypotheses, Weber's is the most frequently quoted : the decrease in ocular tension determined by the use of miotic drugs in primary 
glaucoma is due to a better outflow of the aqueous humour through Schlemm's canal resulting from the pulling away of the root of the iris from the posterior surface of the cornea. The prompt and, in some instances, considerable diminution of tension in cases of glaucoma with gross anatomical changes at the filtration angle, as in cases of synechiae of the root of the iris with the posterior surface of the cornea, or in cases where the canal of Schlemm is absent, as in hydrophthalmia, puts a limit to the validity of this hypothesis. Similarly, Hamburger's hypothesis, according to which miotic drugs favour the opening of the lymphatic pathways of the iris through an increase of the absorbing surface of this membrane, does not explain the diminution of ocular tension, particularly in those cases wherein the uveal tissue shows large areas of atrophy. The demonstration that the aqueous humour is very similar to a dialysate made the influence of the size of the pupillary diameter on ocular tension a matter of little importance (Duke-Elder). A further hypothesis among those commonly recorded is that of Kuesel and Fortin, by which it is suggested that the hypotensive effect of miotics is due to the contraction of the ciliary muscle by which not only are Fontana's spaces opened up owing to the pull on the scleral spur, but also the arterial inflow is 'reduced in consequence of a compression of the long posterior ciliary arteries as they traverse the muscular network of the ciliary body.

It seems peculiar that so little importance has been attributed to the purely vascular effect exerted by the miotic drugs : this action has been proved experimentally to be characteristic, and nowadays there can be little doubt that changes in the uveal circulation constitute one of the main causes of the development and rise of intra-ocular pressure in glaucoma. This, by the way, was the explanation offered regarding the effect of adrenaline in glaucoma, and it is now clear that this drug acts merely by a modification of the circulatory rate. Dieter is among the few who believe, without, however, giving a very clear explanation, that the effect of pilocarpine and eserine depends only on a simple vascular action. It is to be noted also that Thiel, who found experimentally a dilatatory influence of pilocarpine and eserine on the uveal vessels, is of the opinion that these drugs remove vascular stasis in glaucoma through a widening of the uveal vessels and an increased arterial " debit." He believes, however, that this action is not responsible for the entire effect and that further factors, such as a greater unfolding of the iris, are involved.

The problem of the action of miotics and mydriatics in glaucoma is substantially connected with the development and rise of intraocular pressure in this disease. In previous experimental 
researches I have already formulated some considerations about the pathogenesis of this symptom, suggesting that one of the main causes is an alteration in the uveal circulatory " debit." For this reason, in the present paper attention is drawn to the vascular action of the most common miotic and mydriatic drugs, analysing in particular their effect in glaucoma.

\section{Experimental Findings}

The eyes of albinotic rabbits were studied and, in order to obtain experimental demonstrations of the vascular effects of adrenaline, pilocarpine, eserine and atropine on the iris, the ciliary body and choroid, the following techniques were adopted.

\section{I}

Watery solutions of 1 per cent. atropine, 2 per cent. pilocarpine, 0.5 per cent. eserine were instilled several times into the conjunctival sac of the experimental animals, and some drops of adrenaline in $1: 1000$ solution were injected under the conjunctiva. Subsequently, after half an hour, one, and two hours, when an intense miotic or mydriatic effect had appeared, the eyes were examined with the slit-lamp, the light from which was filtered through a chamber filled with copper sulphate solution and a Uviol filter. The vessels of the iris, which were of a black bluish colour in the filtered light, were examined through a corneal microscope (ocular 2, objectives 4 and 6 Zeiss).

From biomicroscopical examination, the following observations were made :

\section{Adrenaline (Fig. I).}

Both the circulus iridis major and the anterior arterioles branching radially from this circle were very thick and winding in comparison with the control eye. Near the pupillary border and, less dense, in the ciliary portion of the iris, one could, with strong magnification, make out the presence of a fine network of capillaries running parallel to the pupillary border. Contrary to Leber's findings, I could observe that this network, especially near the pupillary border, permits the formation of anastomoses between the terminal branches of the anterior arteries of the iris. Just above the pupillary border some small capillary arches were found that could likewise be observed in the control eye, although limited in number.

\section{Pilocarpine and eserine (Figs. 5 and 8)}

Observations with these two drugs are considered together because the biomicroscopic findings were analogous. In contrast to the control eye, it was found that the circulus iridis major and the anterior radial iridal arterioles as well as the two trunks of 


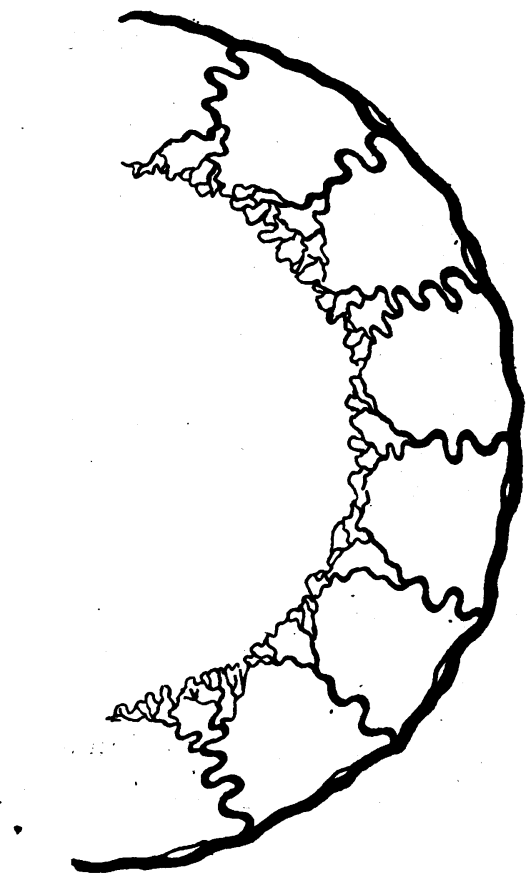

FIG. 1 .

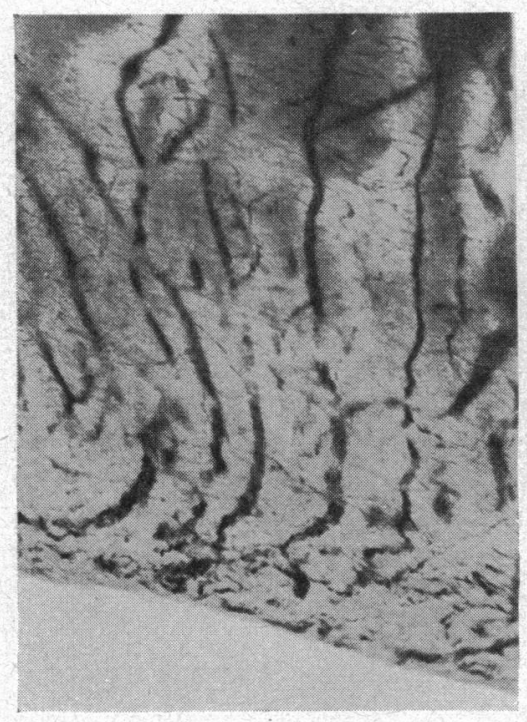

FIG. 3.

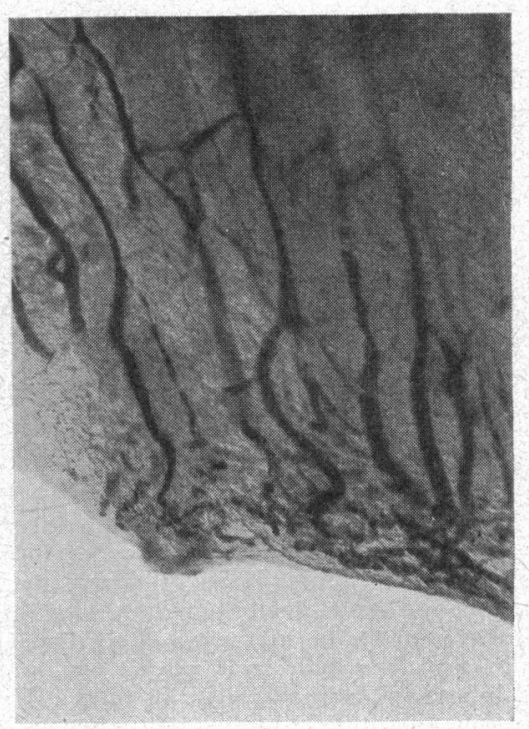

FIG. 2 .

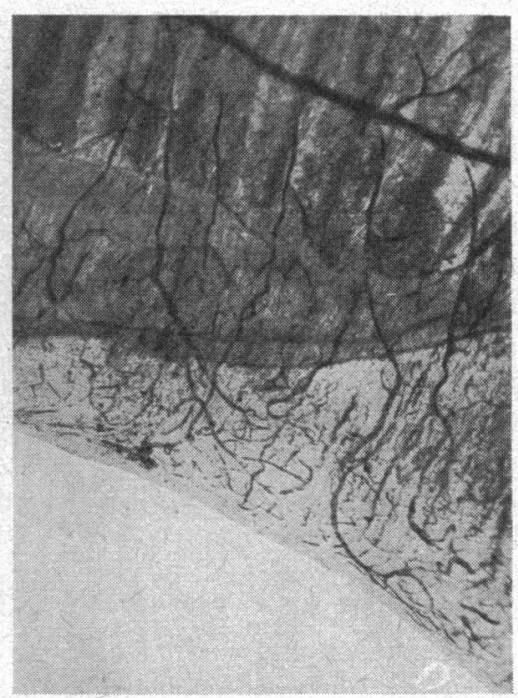

FIG. 4.

Adrenaline: Partly schematic drawing of the vessels of the iris as seen with the slit-lamp (Fig. 1), and microphotographs of the iris after the benzidine reaction (Figs. 2-4). The dilatation of both the large vessels and the capillaries accompanied by the appearance of new vascular districts, especially in the pars pupillaris is characteristic. 


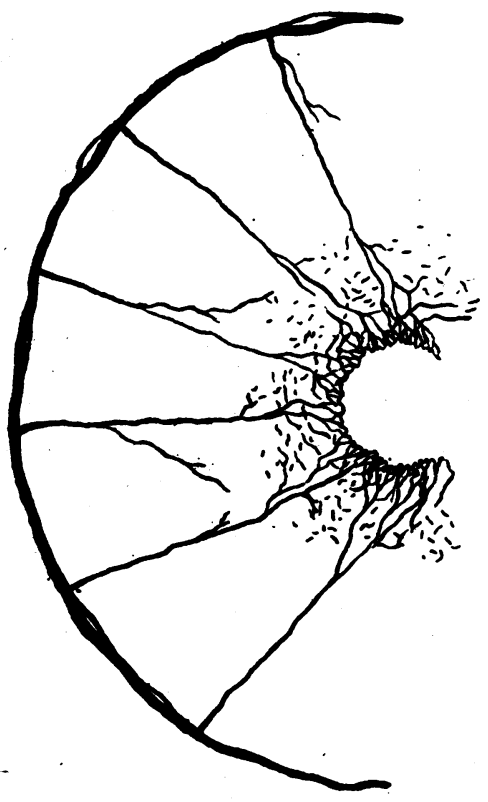

FIG. 5.

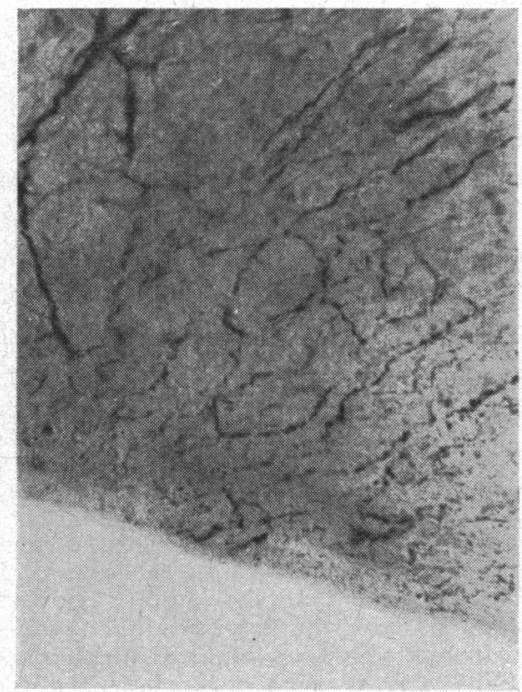

FIG. 6.

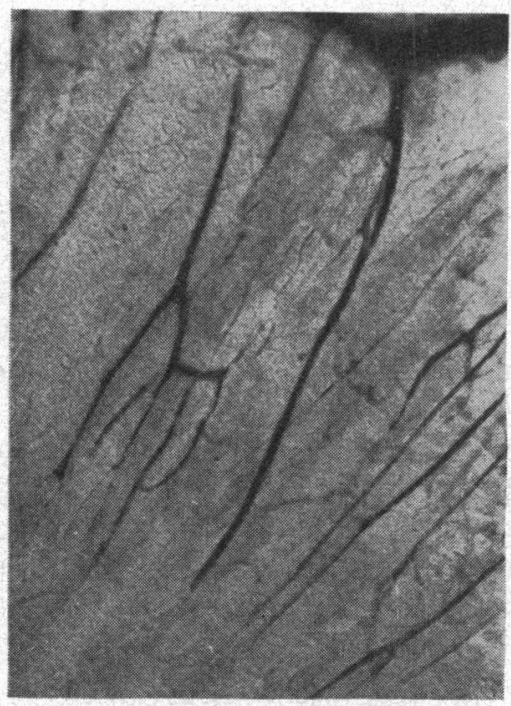

Pilocarpine: Partly schematic drawing of the vessels of the iris as seen with the slit-lamp (Fig. 5). and microphotographs of the iris after the benzidine reaction. Presence of numerous fine capillaries over the whole surface of the iris (Fig. 6), while the larger radial vessels appear normal in size and even reduced (Fig. 7). 
the long posterior ciliary arteries which form the circulus iridis major in the rabbit did not appear dilated, whereas near the pupillary border these vessels divided in numerous small capillary arches. Moreover, towards the ciliary portion among the anterior radial arteries numerous small vessels were observed, forming a sort of capillary network.

\section{Atropine (Fig. 11)}

Here one is struck by 'an abnormal dilatation of the circulus iridis major and of the anterior arteries of the iris. I could not see any capillary network as in the preceding experiments. Near the pupillary region, however, I found some'loop-formed arches, as are seen in normal eyes.

\section{II}

The eyes were subsequently enucleated from the surviving animals. The globes were cut parallel to the equator a few $\mathrm{mm}$. behind the limbus. The lens and vitreous body were carefully removed. The iris as well as the retina and the choroid were detached from their ivases in small rectangular fragments and examined with the dissection microscope. The microscopical findings were mostly analogous to those obtained biomicroscopically, so far as the anterior surface of the iris was concerned.

\section{Adrenaline (Figs. 2-4)}

The ciliary processes, in comparison with the control eye, appeared congested not only because of the dilatation of the arterioles but also because of an increase in their number. Near the pupillary border and throughout the whole surface of the iris I found tiny capillaries which did not occur in the control eye.

Pilocarpine and eserine (Figs. 6, 7, 9, 10).

The striking feature of the microscopical picture was the presence of numerous very fine capillaries uniting the single arteries, and the presence near the pupillary border of numerous capillary arches resembling a kind of caput Medusae. Inside the ciliary processes I found fewer vascular trunks than with adrenaline, at the most two or three, as occur in the normal eye. I cannot assert with certainty to have found any differences from the normal in the fragments of choroid examined. On the whole, the vascular dilatation here was less intense than after adrenaline and atropine.

Atropine (Figs. 12-13)

Microscopically the thin capillary network seen in the pupillary portion of the iris after the administration of pilocarpine and eserine was not seen, but there were scattered and irregular loopformed capillary arches. In the choroid I observed a vascular dilatation which had been absent in the preceding cases. 


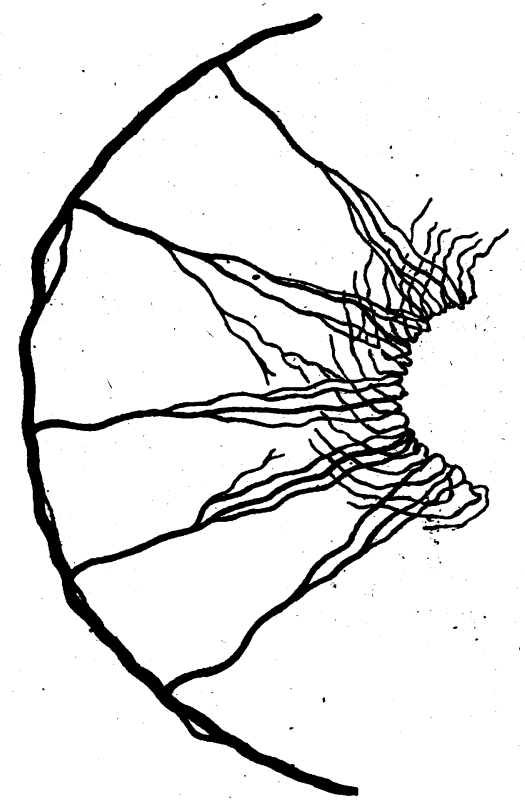

Fig. 8.

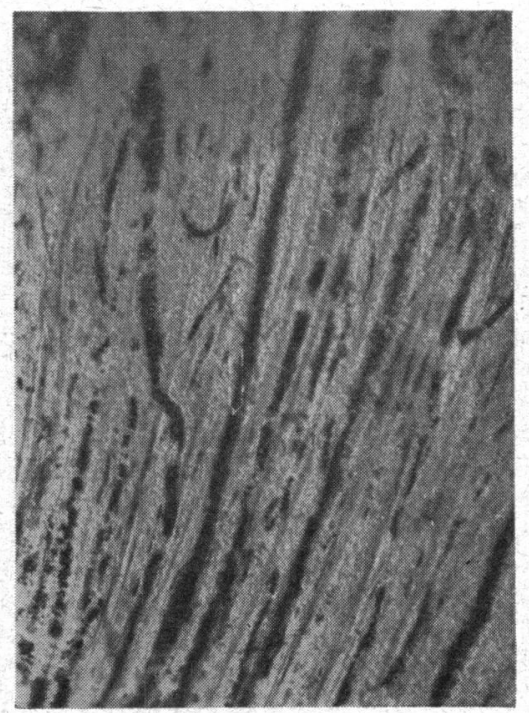

FIG. 9.

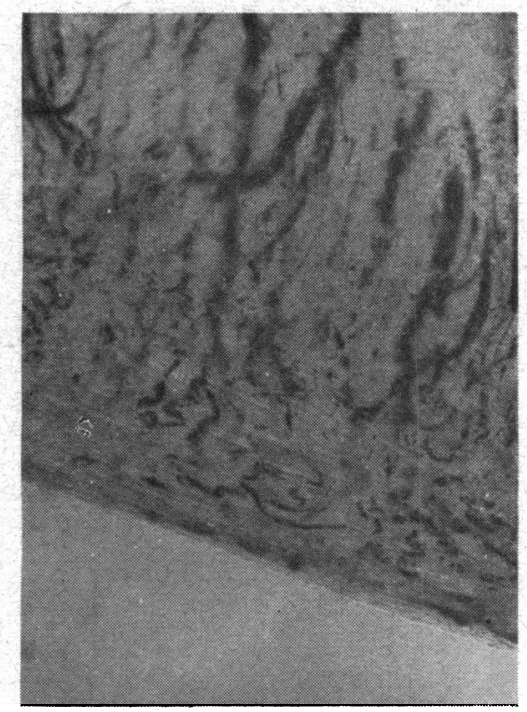

Fig. 10.

Eserine: Partly schematic drawing of the vessels of the iris as seen with the slit-lamp (Fig. 8), and microphotographs of the iris after the benzidine reaction (Figs 9 and 10). Appearance of numerous new capillary districts with dilatation of the smaller vessels, especially in relation to the pars pupillaris, without a corresponding dilatation of the large radial vessels of the iris. 


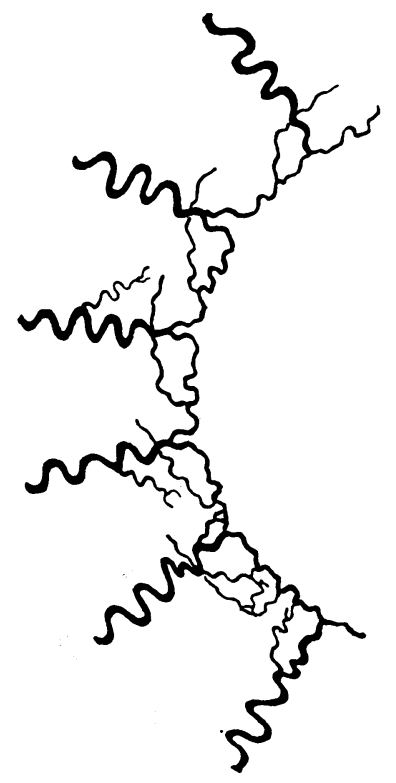

FIG, 11.

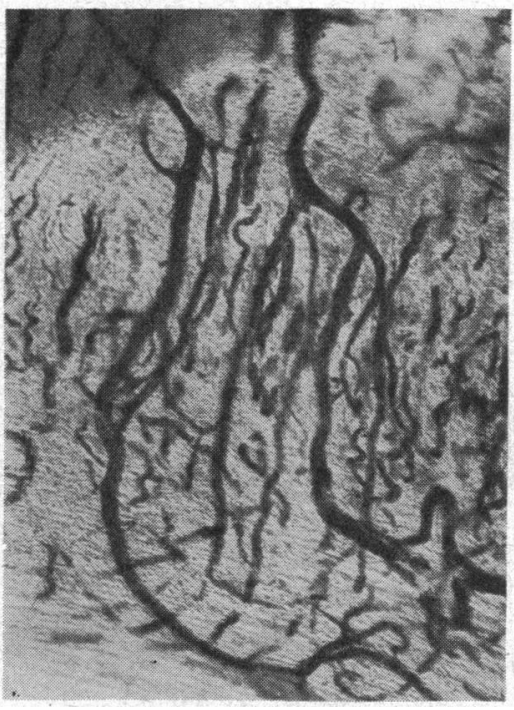

FIG. 12.

Atropine: Partly schematic drawing of the vessels of the iris as seen with the slit-lamp (Fig. 11), and microphotographs of the iris: after the benzidine reaction (Figs, 12 and 13). Considerable vasodilatation and tortuosity of the large vessels of the iris without corresponding dilatation of the smaller vessels, and appearance of new capillar: districts. I'he pars pupillaris does not show any tiny vessels (Fig. 13). 
The fragments were subsequently fixed in a concentrated solution of common salt, sugar and formalin for three days, and finally the benzidine reaction (Pickworth's method) was performed.

From these biomicroscopic and microscopic findings, both in a fresh state and after the benzidine reaction, the following conclusions emerge which, incidentally, are in agreement with those of most investigators:

Adrenaline.-Arterial vasodilatation (probably also venous dilatation) and capillary vasodilatation followed by the appearance of new vascular districts.

Pilocarpine and eserine.-Capillary vasodilatation and opening of new capillary districts, without dilatation of the larger vessels.

Atropine.-Marked arterial vasodilatation (and probably also venous dilatation) without corresponding capillary vasodilatation and without appearance of new capillary districts.

\section{Discussion}

The vasodilator effect obtained by the four drugs is clearly demonstrated by the preceding observations; but while atropine merely acts upon the larger vessels, adrenaline acts upon the capillaries as well, producing not only vasodilatation but also the appearance of new vascular districts. Pilocarpine and eserine exert their action on the capillary vessels with the opening of new vascular sections.

The difficulty in elucidating the effect of these drugs in primary glaucoma, especially with regard to their vascular action, derives from the fact that in this disease the conception of von Hippel and Gruenhagen is usually considered axiomatic. According to it a uveal vasodilatation is constantly followed by a rise in the intra-ocular pressure. As long ago as 1905 Angelucci questioned this physiological conception, which was based merely upon the experimental findings resulting from stimulation of the trigeminal nerve. Modern knowledge of general and ocular physiology has, however, raised doubts as to the validity of this conception.

Although the dialysis theory, i.e., that the aqueous humour is a dialysate in thermodynamic equilibrium with the blood, does not now appear to explain all the facts (Duke-Elder and Davson), it is, however, indisputable that the height of the intra-ocular pressure must be regulated to a large extent by the hydrostatic pressure of the uveal capillaries and by colloid osmotic pressures. According to this conception, which has been generally accepted up to recent times, the intra-ocular pressure is established by the mean level of the capillary pressure less the colloid-osmotic pressure of the plasma proteins (Parsons; Henderson and Starling; Dieter; Duke-Elder; Magitot). The corollary to this 
relationship is that a rise in the level of capillary pressure determines a rise in intra-ocular pressure when the colloid osmotic pressure of the plasma proteins remains unaltered.

General haemodynamic laws inform us that the hydrostatic pressure at any level of the vascular system is " proportional to the sum of resistances the liquid is forced to overcome " (Luciani). The conception of von Hippel and Gruenhagen, which we have already noted, may hold true, according to haemodynamic laws, only in the case of dilatation of the arteries, but not of the capillaries. Here, indeed, haemodynamics show that the sum of resistances increases instead of diminishing, as in the case of arterial dilatation, in spite of a considerable increase of the vascular bed. The corollary to this fundamental physiological fact is that two different variations in intra-ocular pressure occur according to whether there is an arterial or a capillary vasodilatation. In the former case, the sum of resistances encountered by the blood decreases, and therefore the mean capillary pressure increases, and this is followed by a rise in intra-ocular pressure; in the latter case, in spite of the considerable dilatation of the vascular bed, the sum of resistances increases and is followed by a fall in hydrostatic capillary pressure, and consequently in intraocular pressure.

The importance of these facts must be clearly remembered in any discussion on the regulation of the tension of the eye. The functional independence of the arterial circulation from the capillary circulation is certainly one of the most essential features in maintaining the intra-ocular pressure at a constant level, in spite of occasional sudden haemodynamic variations. In pathological conditions, as in primary chronic glaucoma, we must not forget that the rise of capillary pressure is one of the fundamental experimental findings (Dieter). Notwithstanding numerous experimental researches, no variation in blood composition or in the colloid osmotic pressure of the plasma proteins has been found in this disease.

The rise of the capillary pressure level in glaucoma, in haemodynamic terms, may be considered as a "diminution of the sum of peripheral resistances encountered by the blood as far as the last capillary barrier."

From my previous experimental researches I concluded that one of the numerous causes of the rise in intra-ocular pressure in the glaucomatous eye is such a diminution of the sum of resistances. According to this hypothesis the cause is a reduction of the uveal capillary bed owing to the obliteration of numerous vascular districts. This hypothesis was based on the fact that in typical primary (simple) chronic glaucoma the choroid becomes thinner 
and the capillaries are obliterated and disappear, as was particularly stressed by Elschnig. Further evidence is the fact that no rise in capillary pulse volume could be registered photoplethysmographically on the inspiration of amyl nitrite.

The effect of the action of pilocarpine and eserine, adrenaline and atropine, so characteristic in this disease, can be related with this essential aspect of the development and rise of intra-ocular pressure.

Pilocarpine ( 2 per cent.) and eserine ( 0.5 per cent.).

From a vascular point of view these drugs act by modifying the capillary circulatory " debit." As was already mentioned in the experimental part of this paper, their vasodilator action makes itself evident on the capillary vessels, even favouring the opening up of new vascular reserve sections. This was suggested by Krogh in 1924 at the Deutsche Ophthalmologische Gesellschaft, in view of the fact that the instillation of these drugs raises the albumen content of the aqueous humour, and has also been experimentally confirmed by Angelucci, Wessely, Dieter, and others. As has already been mentioned, the dilatation of the capillary bed will give rise to an increase in the sum of resistances and this increase cannot be compensated by a growth of the vascular bed. Consequently we shall note a fall in the level of the capillary pressure.

Indeed, by measuring the capillary pressure entoptically in glaucomatous patients Dieter found that this pressure falls after the instillation of miotic drugs. Again, Thomassen has recently observed in glaucomatous patients that the instillation of pilocarpine and eserine lowers the venous pressure in the episcleral vessels, whereas it is without any influence on the pressure in the episcleral arteries. Moreover, this author found experimentally that the lowering of intra-ocular pressure was secondary to the decrease in venous pressure.

Finally, the present hypothesis that pilocarpine and eserine increase the sum of resistances by dilating and opening new capillary districts may explain some experimental findings that have not yet found a solution. Gala, by means of sodium iodide, and Thiel, by means of fluorescein, found that in glaucomatous eyes after the instillation of miotic drugs the outflow of these substances into the aqueous is lessened, thus confirming Hess's entoptic findings as to the slowing of the blood flow.

In fact, following general physiological principles, the increase of the capillary bed brought about by pilocarpine and eserine will lower the capillary pressure as well as the rate of flow. 
Atropine (1 per cent.).

My findings show that this drug produces vasodilatation in the larger vessels and has no influence whatever on the capillary bed. That its action on the capillaries is almost without effect is demonstrated by the fact that the instillation of this drug does not alter the concentration of albumen in the aqueous, as was found by Dieter and confirmed quite recently by Stocker. According to general haemodynamic laws, the arterial vasodilatation induced by this drug will determine a diminution of the sum of resistances in the glaucomatous eye. Dieter, indeed, found experimentally that the capillary pressure rises with the instillation of atropine. Since this occurs in a third of all glaucomatous patients, and when it does there develops at the same time an acute attack of raised tension, we may infer that in these cases the capillary bed, owing to its severe impairment, is no longer able to neutralize the diminution of the sum of resistances which follows the vasodilatation of the large arterial vessels. The consequence will be a rise in intra-ocular pressure and an infringement of the "law of circulatory rate," i.e., the amount of blood passing through the the arterial section is not exactly equal to the amount passing during the same time through the venous section of the system. This would be comparable to the onset of certain pulmonary oedemas occurring in consequence of the altered ratio between the amount of blood passing through the pulmonary veins and the amount passing during the same time through the arterial pulmonary system.

Adrenaline (1:1000).

The vascular effects of adrenaline are to some extent similar to those already inferred for pilocarpine and eserine as well as for atropine. It is beyond doubt-and most investigators are of this opinion-that the greatest hypotensive effect obtained with this drug becomes evident during the period of maximal arterial and capillary vasodilatation. Like atropine, this drug actually dilates the large arterial vessels, thus diminishing the sum of resistances; but like pilocarpine and eserine it opens new vascular reserve sections, thus increasing the capillary surface. But the final result is an increase of the sum of resistances, owing to the growth of the capillary bed, thus bringing about a decrease of the mean capillary hydrostatic pressure.

This drug is probably contra-indicated in acute glaucoma because under certain experimental conditions, as was noticed by Poos, it produces an excessive permeability in the capillaries for the plasma proteins, and thus will determine a marked rise in intra-ocular pressure. In fact, as the balance of distribution is 
almost equal inside and outside the vessêls, an annulment of the osmotic membranes takes place, as if a river of fresh water enters into the sea. The level of the intra-ocular pressure would thus be determined only by the height of the vascular hydrostatic pressure, no longer antagonized by the colloid osmotic pressure of the plasma proteins, as in the equilibrium described by Henderson and Starling.

Finally, I wish to emphasize that the hypotheses so far put forward represent only an attempt to interpret the vascular action of these four drugs, and that further experimental investigation is required.' As long as our knowledge of the origin and nature of the intra-ocular fluid is imperfect, however, it is impossible to offer a definite and complete explanation regarding the effects of these drugs, since the questions raised are intimately connected with the more essential problem of the development and rise of the intra-ocular pressure.

\section{SUMmaRY}

1. Pilocarpine and eserine determine a vasodilatation and the opening of new capillary districts followed by an increase of the capillary bed without, however, dilating the large vessels. In the light of general haemodynamic knowledge this causes an increase of the sum of resistances in the circulation, in spite of a considerable growth of the circulatory bed. The fundamental corollary to this action is the fall of the mean capillary hydrostatic pressure and, therefore, of the ocular tension, as occurs in primary chronic glaucoma.

2. Atropine determines a dilatation of the large vessels without any corresponding capillary dilatation, and without opening up new vascular districts. According to haemodynamic laws, this brings about a diminution of the sum of resistances in the circulation, and therefore an increase of the mean capillary hydrostatic pressure, whenever the capillary bed, as in chronic glaucoma, is severely impaired and is no longer able to cope with such difficulties.

3. Adrenaline determines a dilatation both of the large vessels and of the smaller capillaries, followed by the opening of new vascular districts and by a growth of the circulatory bed. Like atropine, this drug dilates the large arterial vessels, thus diminishing the sum of resistances; but, like pilocarpine and eserine, it opens new vascular reserve sections, thus increasing the capillary surface. But the final resulting effect is the increase of the sum of resistances owing to the growth of the capillary bed, thus bringing about a decrease of the mean capillary hydrostatic pressure, and therefore of ocular tension. 


\section{- REFERENCES}

ANGELUCCI (1905).-Encyclopédie française.

BAILliart and Bidault (1939).- In Traité d'Ophtalmologie, 8. Masson.

Colle, Duke-Elder, P. M., and Duke-Elder, W.S. (1931).-Jl. Physiol., $71,1$.

Colombo (1923).-Boll. d'Ocul., 2.

Cristini, G. (1947)-Ann. d'Ocul., 80, 530.

- (1948).-Gior. Ital. Oftal., 1, 5.

(1948).-Ibid., 1, 385 .

DiETE R (1925).-Arch.f. Augenheilk., 96, 179.264.

DUKE-ELDER, W. S. (1938). - Text-Book of Ophthalmology, Kimpton.

DukE-Elder, W. S. and Davson, H. (1948).-Brit. Jl. Ophthal., 32, 555.

ELSCHNIG.-Henke Lubarsch, 11, 911.

FORTIN (1929).-Arch. d'Oftal., B.A., 359, 454.

FORT (1939).-Semana Medica., 1, 1128.

Gala (1939).- Quoted by Magitot in Traité d'Ophtalmologie, 6, 264. Masson.

HAM BURGER (1923).-Med. Klin., 19, 1215.

(1924).-Ibid.. 20, 267, (1925).-Ibid., 21, 1495,

Henderson and Starling (1904).-Jl. Physiol., 31, 305.

v. HIPPEL and GRUENHAGEN (1868).-Arch.f. Ophthal., 14, 219.

KoEllner (1916).-Arch. f. Augenheilk., 80, 245.

KUESEL (1906).-Klin. Monatsbl. f. Augenheilk., 44, 80, 236.

Lucian1-Fisiologia dell'uomo, 1, 381.

Magitot (1939).-Traitê d'Ophtalmologie, 11. Masson.

MiCHAIL and VANCEA (1926).-Ann.d'Ocul., 126, 561,

Parsons (1902). - The Pathology of the Eye. London.

Poos (1931). -Arch. f. Ophthal., 127, 489.

STOCKER (1947).-Arch. Ophthal., 37, 583.

THIEL (1924).-Zentralbl.f.d. ges. Ophthal., 12, 305.

Kurzes Handb.f. Ophthal. (Glaukom.), 781.

Thomassen (1947).-Acta Ophthal., 25, 221.

(1947).-Ibid., 25, 252.

WEBER (1877).-Arch.f. Ophthal., 23, 1.

WESSELY (1918).-Arch.f Augenheilk., 83, 99.

\section{SLIT-LAMP EXAMINATION OF THE VITREOUS AND THE FUNDUS*}

BY

\section{H. GoldmanN \\ BERNE}

Examination of the vitreous body and of the fundus with the help of the slit-lamp enables us to understand better some pathological pictures, and often facilitates a differential diagnosis. Since more details are being revealed by this method, pathological changes can be detected early. Moreover, stereoscopic examination of the fundus is made possible by a cheap additional device to the slit-lamp which not only does the work of a binocular ophthalmoscope of Gullstrand, but gives better results.

* Lecture given May 8, 1948, to members of the British Faculty of Ophthalmologists at Berne. 